\title{
Improve Algoritma Hodgson Untuk Meminimasi Jumlah Job Terlambat Pada Penjadwalan Flow shop
}

\author{
Dian Setiya Widodo \\ Program Studi Teknik Manufaktur, Politeknik 17 Agustus Surabaya \\ Jl. 45, Gedung N\&P, Semolowaru, Sukolilo, Surabaya, Jawa Timur 60118 \\ Korespondensi penulis, surel: diansetiyawidodo@yahoo.com
}

\begin{abstract}
Since Johnson published a paper in 1954, the problem of job scheduling has received the attention of hundreds of practitioners and researchers, as one of the most studied topics in Operation research. Several heuristic studies have discussed the problem of flow shop scheduling to minimize the completion time (makespan). In this paper, we consider the problem of pure flow shop scheduling to minimize the number of jobs of tardy. We have developed a Hudson algorithm for minimization solution the number jobs of tardy. Hodgson's improved Heuristic algorithm was tested and compared to the EDD priority rule. The Numerical experimental results show the new algorithm provides a better solution than priority EDD. The improving Hodgson algorithm gives a minimum number of tardy jobs.
\end{abstract}

Keywords: Flow shop, The number jobs of tardy, Hodgson

\begin{abstract}
Abstrak
Sejak Johnson menerbitkan makalah pada tahun 1954, masalah penjadwalan pekerjaan telah mendapat perhatian dari ratusan praktisi dan peneliti, sebagai salah satu topik yang paling banyak dipelajari dalam Penelitian Operasi. Beberapa penelitian heuristik telah membahas masalah penjadwalan flow shop meminimalkan waktu penyelesaian (makespan). Pada makalah ini, kami mempertimbangkan masalah penjadwalan pure flow shop untuk meminimalkan jumlah job yang terlambat. Kami telah mengembangkan algoritma hodgson untuk menghasilkan solusi minimum jumlah job yang terlambat. Algoritma Heuristik improve hodgson ini diuji dan dibandingkan dengan dengan aturan prioritas EDD. Hasil percobaan numerik menunjukkan Algoritma improve hodgson lebih baik dari aturan EDD. Algoritma improve hodgson menghasilkan minimum jumlah pekerjaan terlambat.
\end{abstract}

Kata kunci: Flow shop, jumlah job terlambat, Hodgson

\section{Pendahuluan}

Penjadwalan merupakan pengaturan waktu pada mesin yang mencakup kegiatan mengalokasikan fasilitas dan peralatan. Penjadwalan berguna untuk menentukan urutan pekerjaan [1]. Fungsi penjadwalan yaitu memproses produk sesuai dengan waktu yang diinginkan, memprediksi kesiapan setiap sumber daya yang diperlukan [2]. Berdasarkan aliran produksi, penjadwalan di klasifikasi menjadi flow shop dan job shop. Harto, et al. [3] menyatakan bahwa pada penjadwalan job shop umumnya menggunakan algoritma aktif dan non delay. Husen, et al. [4] menyatakan bahwa pada penjadwalan job shop dapat menggunakan algoritma simulated annealing. Penjadwalan flow shop adalah penjadwalan di mana semua job yang akan dikerjakan melalui urutan proses operasi yang sama [1]. Umumnya performansi dari penjadwalan yaitu untuk meminimalkan flow time, makespan, maximum tardiness, job tardy dan lateness [5]. Pengertian dari flow time itu sendiri ialah waktu yang dibutuhkan sebuah pekerjaan untuk berada di dalam sebuah sistem produksi. Sedangkan waktu yang dibutuhkan untuk menyelesaikan seluruh pekerjaan (job) adalah makespan [6]. Dalam 
penjadwalan sendiri terdapat beberapa kategori berdasarkan sistem produksi diantaranya ialah single machine, flow shop dan job shop.

Aturan-aturan prioritas dasar pada penjadwalan produksi umumnya menggunakan metode Shortest Processing Time (SPT), Longest Processing Time (LPT), Earliest Due date (EDD), Aturan Slack [2] [7]. Beberapa metode tersebut dapat digunakan untuk beberapa penyelesaian solusi tertentu sebagai contoh yaitu meminimumkan mean flow time, makespan, tardiness, mean tardiness, maximum tardiness, dan number of tardy job. Metode SPT digunakan untuk meminimalkan mean flow time. Selanjutnya jika untuk meminimalkan makespan dan mean flow time dapat menggunakan metode LPT lalu dilanjut dengan metode SPT [8]. Jika untuk mengurangi tardiness dapat menggunakan aturan slack. Jika untuk mengurangi mean tardiness dapat menggunakan metode SPT, EDD, dan slack lalu dilanjut menggunakan algoritma genetika [9].

Beberapa algoritma pure flow shop yang telah diteliti adalah Johnson [10], Campbell, et al. [11], Gupta [12], Dannenbring [13], Logendran and Nudtasomboon [14], Pour [15], Nawaz, et al. [16] [17], simulated annealing [4] dan Branch and Bound [18]. Penelitian tersebut umumnya menggunakan kriteria minimasi makespan. Makespan adalah total wa ktu yang dibutuhkan untuk menyelesaikan seluruh job [5][7]. Selain itu ada beberapa penelitian yang mambahas tentang minimasi job yang terlambat antara lain Moore [19] membuat algoritma untuk minimasi jumlah job yang terlambat. Algoritma ini yang mengawali cikal bakal algoritma hodgson. Ho and Chang [20] telah melakukan penelitian untuk meminimasi jumlah job yang terlambat pada masalah single stage parallel mesin. Lodree Jr, et al. [21] telah melakukan penelitian untuk meminimasi jumlah job yang terlambat pada masalah flow shop dinamis. Azizoglu, et al. [22] telah melakukan penelitian untuk meminimasi dua kriteria performansi maximum earliness dan number of tardy jobs pada single mesin. M'Hallah and Bulfin [23], M'Hallah and Bulfin [24] telah melakukan penelitian untuk meminimasi Total bobot jumlah job yang terlambat pada masalah single machine. Li and Chen [25] telah melakukan penelitian minimasi job tardy untuk masalah single stage mesin paralel dengan due date seragam. Aydilek, et al. [26] telah melakukan penelitian meminimasi jumlah job yang terlambat untuk satu mesin dengan waktu proses yang tidak diketahui. Umumnya mengurangi number of tardy job dapat menggunakan metode algoritma Hodgson [27].

Beberapa penelitian untuk menimimasi jumlah job yang terlambat telah banyak dilakukan. Sayangnya, penelitian tentang minimasi menimimasi jumlah job yang terlambat kebanyakan masih dipakai untuk masalah single mesin atau single stage. Pada penelitian terdahulu, algoritma Hodgson merupakan algoritma heuristik terbaik dalam menghasilkan solusi minimasi menimimasi jumlah job namun khusus untuk kasus single machine [19]. Dalam penelitian ini, kami mengembangkan algoritma heuristik Hodgson pada penjadwalan produksi flow shop guna menemukan solusi minimasi jumlah job terlambat. Tujuan dari artikel ini adalah mengembangkan algoritma heuristik Hodgson pada penjadwalan produksi flow shop guna menemukan solusi minimasi jumlah job terlambat. Algoritma yang telah dikembangkan (improve Hodgson) dibandingkan dengan aturan prioritas EDD.

\section{Metode Penelitian}

Pada dasarnya algoritma Hogdson ini digunakan pada penjadwalan single machine. Dalam penelitian ini algoritma Hodgson digunakan untuk kasus flow shop $n$ - 
machine. Beberapa bagian algoritma telah dimodifikasi oleh peneliti. Tahapan penjadwalan flow shop untuk meminimasi jumlah job adalah sebagai berikut:

1. Setiap pekerjaan $\mathrm{j}$ dihitung total waktu proses $(\mathrm{Tj})$ sesuai dengan persamaan 1. $t_{i j}$ Menunjukkan waktu proses yang diperlukan pekerjaan $\mathrm{j}$ di mesin $\mathrm{i}$.

$$
T j=\sum_{i=1}^{m} t_{j i}
$$

2. Urutkan Job sesuai dengan due date yang paling kecil.

3. Lakukan penjadwalan. Hitung lateness berdasarkan persamaan 2 Jika tidak ada job yang terlambat maka urutan job tersebut sudah optimal. Jika ada yang terlambat lanjut ke langkah 4.

$L j=C j-d j$

Jika $\mathrm{Lj} \leq 0$, artinya saat penyelesaian memenuhi batas akhir.

Jika $\mathrm{Lj}>0$, artinya saat penyelesaian melewati batas akhir (Terlambat).

4. Jika job j pertama kali terlambat (saat penyelesaian melewati batas akhir $(\mathrm{Lj}>0)$ ), maka cari job a sebelum job $\mathrm{j}$ yang mempunyai waktu total pengerjaan paling lama. Kemudian hilangkan $j o b$ a tersebut, untuk dikerjakaan setelah semua job tidak ada lagi yang terlambat setelah semuanya diproses

5. Lakukan penjadwalan kembali seperti langkah 3 tanpa job yang terlambat sebelumnya, lakukan langkah 4 dan 5 hingga job tidak ada yang terlambat atau hanya menyisakan 1 job yang terlambat diurutan paling belakang.

6. Letakkan semua job yang dihilangkan karena keterlambatan tadi dalam urutan paling akhir di urutan penjadwalan yang sudah terbentuk.

7. Hitung performansi kriteria jumlah job yang terlambat berdasarkan persamaan 3

$$
\begin{aligned}
& N t=\sum_{j=1}^{n} N j \\
& \mathrm{Nj}=1 \text { jika } \mathrm{Lj}>0 \\
& \mathrm{Nj}=0 \text { jika } \mathrm{Lj} \leq 0
\end{aligned}
$$

\section{Hasil dan Pembahasan}

Percobaan numerik dilakukan dengan melakukan penjadwalan 10 job flow shop 2 mesin. Data percobaan numerik dapat dilihat pada Tabel 1.

Tabel 1 Data Percobaan Numerik

\begin{tabular}{cccc}
\hline Job & Mesin 1 & Mesin 2 & Due Date \\
\hline 1 & 5 & 1 & 15 \\
2 & 4 & 2 & 12 \\
3 & 5 & 1 & 13 \\
4 & 3 & 3 & 14 \\
5 & 6 & 2 & 11 \\
6 & 7 & 1 & 17 \\
7 & 3 & 2 & 20 \\
8 & 2 & 2 & 18 \\
9 & 5 & 1 & 17 \\
10 & 4 & 2 & 22 \\
\hline
\end{tabular}


Langkah-langkah penyelesaian meminimasi jumlah job yang terlambat pada masalah flow shop adalah sebagai berikut:

1. Menghitung total waktu proses $(\mathrm{Tj})$ setiap pekerjaan $\mathrm{j}$. total waktu proses $(\mathrm{Tj})$ dihitung sesuai dengan persamaan 1 . Rekapitulasi perhitungan total waktu proses dapat dilihat pada Tabel 2. Contoh perhitungan $\mathrm{Tj}$ dapat dilihat berikut ini.

$\mathrm{T}_{1}=\mathrm{t}_{11}+\mathrm{t}_{12}$

$=5+1=6$

Tabel 2 Rekapitulasi perhitungan total waktu proses

\begin{tabular}{cccc}
\hline Job & Mesin 1 & Mesin 2 & $\mathrm{Tj}$ \\
\hline 1 & 5 & 1 & 6 \\
2 & 4 & 2 & 6 \\
3 & 5 & 1 & 6 \\
4 & 3 & 3 & 6 \\
5 & 6 & 2 & 8 \\
6 & 7 & 1 & 8 \\
7 & 3 & 2 & 5 \\
8 & 2 & 2 & 4 \\
9 & 5 & 1 & 6 \\
10 & 4 & 2 & 6 \\
\hline
\end{tabular}

2. Urutkan $J o b$ sesuai dengan due date yang paling kecil. Urutan berdasarkan due date terkecil adalah $\mathrm{J}_{5}, \mathrm{~J}_{2}, \mathrm{~J}_{3}, \mathrm{~J}_{4}, \mathrm{~J}_{1}, \mathrm{~J}_{6}, \mathrm{~J}_{9}, \mathrm{~J}_{8}, \mathrm{~J}_{7}, \mathrm{~J}_{10}$.

3. Melakukan penjadwalan berdasarkan urutan due date terkecil dan menghitung lateness berdasarkan persamaan 2 berdasarkan urutan job pada langkah 2 . Penjadwalan dan perhitungan lateness dapat dilihat pada Tabel 3. Contoh perhitungan $\mathrm{Tj}$ dapat dilihat berikut ini.

$\mathrm{L}_{5}=\mathrm{C}_{5}-\mathrm{d}_{5}$

$$
=6-11=-5
$$

Tabel 3 Penjadwalan dan perhitungan lateness

\begin{tabular}{|c|c|c|c|c|c|c|c|c|c|}
\hline \multirow[b]{2}{*}{$J o b$} & \multirow{2}{*}{$\begin{array}{c}\text { Mesin } 1 \\
\quad(\mathrm{tj} 1)\end{array}$} & \multirow{2}{*}{$\begin{array}{c}\text { Mesin } 2 \\
(\mathrm{tj} 2)\end{array}$} & \multirow[b]{2}{*}{$\mathrm{Tj}$} & \multirow[b]{2}{*}{$\mathrm{dj}$} & \multicolumn{2}{|c|}{ Mulai } & \multicolumn{2}{|c|}{ Selesei } & \multirow[b]{2}{*}{$\mathrm{Lj}$} \\
\hline & & & & & M1 & $\mathrm{M} 2$ & M1 & $\mathrm{M} 2$ & \\
\hline 5 & 4 & 2 & 6 & 11 & 0 & 4 & 4 & 6 & -5 \\
\hline 2 & 3 & 2 & 5 & 12 & 4 & 7 & 7 & 9 & -3 \\
\hline 3 & 5 & 4 & 9 & 13 & 7 & 12 & 12 & 16 & 3 \\
\hline 4 & 4 & 7 & 11 & 14 & 12 & 16 & 16 & 23 & 9 \\
\hline 1 & 1 & 1 & 2 & 15 & 16 & 23 & 17 & 24 & 9 \\
\hline 6 & 7 & 3 & 10 & 17 & 17 & 24 & 24 & 27 & 10 \\
\hline 9 & 2 & 1 & 3 & 17 & 24 & 27 & 26 & 28 & 11 \\
\hline 8 & 2 & 2 & 4 & 18 & 26 & 28 & 28 & 30 & 12 \\
\hline 7 & 1 & 2 & 3 & 20 & 28 & 30 & 29 & 32 & 12 \\
\hline 10 & 1 & 1 & 2 & 22 & 29 & 32 & 30 & 33 & 11 \\
\hline
\end{tabular}

4. Job 3 merupakan job pertama kali terlambat (saat penyelesaian melewati batas akhir $(\mathrm{Lj}>$ $0)$ ). Selanjutnya mencari job yang mempunyai waktu total waktu pengerjaan paling 
lama pada job 3 dan urutan sebelum. Berdasarkan lateness positif pertama urutan pekerjaan adalah $\mathrm{J}_{5}, \mathrm{~J}_{2}$ dan $\mathrm{J}_{3}$. Waktu terbesar adalah pada job 3 . Kemudian hilangkan job 3 tersebut.

5. Melakukan penjadwalan kembali seperti langkah 3 hingga job tidak ada yang terlambat atau hanya menyisakan 1 job yang terlambat diurutan paling belakang. Rekapitulasi iterasi dan urutan job dapat dilihat pada Tabel 4.

Tabel 4 Rekapitulasi iterasi dan urutan job

\begin{tabular}{|c|c|c|c|c|c|c|c|c|c|c|c|}
\hline \multirow{2}{*}{$\begin{array}{c}\text { Iterasi } \\
\text { Ke }\end{array}$} & \multicolumn{10}{|c|}{ Urutan $J o b$} & \multirow{2}{*}{$\begin{array}{c}\text { Job yang } \\
\text { dihilangkan } \\
-\end{array}$} \\
\hline & 5 & 2 & 3 & 4 & 1 & 6 & 9 & 8 & 7 & 10 & \\
\hline Iterasi 2 & 5 & 2 & 4 & 1 & 6 & 9 & 8 & 7 & 10 & & 3 \\
\hline Iterasi 3 & 5 & 2 & 1 & 6 & 9 & 8 & 7 & 10 & & & 4 \\
\hline Iterasi 4 & 5 & 2 & 1 & 9 & 8 & 7 & 10 & & & & 6 \\
\hline
\end{tabular}

6. Letakkan semua job yang dalam urutan paling akhir. Sehingga urutan job adalah $\mathbf{J}_{5}, \mathrm{~J}_{2}, \mathrm{~J}_{1}, \mathrm{~J}_{9}, \mathrm{~J}_{8}, \mathrm{~J}_{7}, \mathrm{~J}_{10}, \mathrm{~J}_{3}, \mathrm{~J}_{4}, \mathrm{~J}_{6}$

7. Hitung performansi kriteria urutan job adalah $\mathbf{J}_{5}, \mathbf{J}_{2}, \mathbf{J}_{1}, \mathbf{J}_{9}, \mathbf{J}_{8}, \mathbf{J}_{7}, \mathbf{J}_{10}, \mathbf{J}_{3}, \mathbf{J}_{4}, \mathbf{J}_{6}$ persamaan 3. Rekapitulasi perhitungan performansi improve hodgson dapat dilihat pada Tabel 5 . Contoh perhitungan job yang terlambat sebagai berikut.

$\mathrm{N}_{5}=0$

Tabel 5 Rekapitulasi performansi algoritma improve Hodgson

\begin{tabular}{|c|c|c|c|c|c|c|c|c|c|c|}
\hline \multirow[b]{2}{*}{$J o b$} & \multirow{2}{*}{$\begin{array}{c}\text { Mesin } 1 \\
(\mathrm{tj} 1)\end{array}$} & \multirow{2}{*}{$\begin{array}{c}\text { Mesin } 2 \\
(\mathrm{tj} 2)\end{array}$} & \multirow[b]{2}{*}{$\mathrm{Tj}$} & \multirow[b]{2}{*}{$\mathrm{dj}$} & \multicolumn{2}{|c|}{ Mulai } & \multicolumn{2}{|c|}{ Selesai } & \multirow[b]{2}{*}{$\mathrm{Lj}$} & \multirow[b]{2}{*}{$\mathrm{Nj}$} \\
\hline & & & & & M1 & M2 & M1 & M2 & & \\
\hline 5 & 4 & 2 & 6 & 11 & 0 & 4 & 4 & 6 & -5 & 0 \\
\hline 2 & 3 & 2 & 5 & 12 & 4 & 7 & 7 & 9 & -3 & 0 \\
\hline 1 & 1 & 1 & 2 & 13 & 7 & 9 & 8 & 10 & -3 & 0 \\
\hline 9 & 2 & 1 & 3 & 14 & 8 & 10 & 10 & 11 & -3 & 0 \\
\hline 8 & 2 & 2 & 4 & 15 & 10 & 12 & 12 & 14 & -1 & 0 \\
\hline 7 & 1 & 2 & 3 & 17 & 12 & 14 & 13 & 16 & -1 & 0 \\
\hline 10 & 1 & 1 & 2 & 17 & 13 & 16 & 14 & 17 & 0 & 0 \\
\hline 3 & 5 & 4 & 9 & 13 & 14 & 19 & 19 & 23 & 10 & 1 \\
\hline 4 & 4 & 7 & 11 & 14 & 19 & 23 & 23 & 30 & 16 & 1 \\
\hline 6 & 7 & 3 & 10 & 17 & 23 & 30 & 30 & 33 & 16 & 1 \\
\hline \multicolumn{10}{|c|}{ Total Nt } & 3 \\
\hline
\end{tabular}

Perhitungan algoritma improve Hodgson juga dibandingkan dengan aturan prioritas Earliest Due date (EDD). Hasil perhitungan penjadwalan aturan prioritas EDD dapat dilihat pada Tabel 6 . Hasil Tabel 6 perhitungan penjadwalan produksi aturan prioritas menunjukkan bahwa penjadwalan dengan aturan prioritas EDD menghasilkan 8 dari 10 job terlambat. Sedangkan pada penjadwalan improve hodgson menghasilkan 3 
dari 10 job terlambat. Percobaan ini menunjukkan bahwa algoritma improve hodgson efektif dalam meminimasi jumlah job terlambat pada kasus flow shop.

Tabel 6 Perhitungan penjadwalan aturan prioritas EDD

\begin{tabular}{|c|c|c|c|c|c|c|c|c|c|c|}
\hline \multirow[b]{2}{*}{ Job } & \multirow{2}{*}{$\begin{array}{c}\text { Mesin } 1 \\
(\mathrm{tj} 1)\end{array}$} & \multirow{2}{*}{$\begin{array}{l}\text { Mesin } \\
2(\mathrm{tj} 2)\end{array}$} & \multirow[b]{2}{*}{$\mathrm{Tj}$} & \multirow[b]{2}{*}{$\mathrm{dj}$} & \multicolumn{2}{|c|}{ Mulai } & \multicolumn{2}{|c|}{ Selesei } & \multirow[b]{2}{*}{$\mathrm{Lj}$} & \multirow[b]{2}{*}{$\mathrm{Nj}$} \\
\hline & & & & & M1 & M2 & M1 & M2 & & \\
\hline 5 & 4 & 2 & 6 & 11 & 0 & 4 & 4 & 6 & -5 & 0 \\
\hline 2 & 3 & 2 & 5 & 12 & 4 & 7 & 7 & 9 & -3 & 0 \\
\hline 3 & 5 & 4 & 9 & 13 & 7 & 12 & 12 & 16 & 3 & 1 \\
\hline 4 & 4 & 7 & 11 & 14 & 12 & 16 & 16 & 23 & 9 & 1 \\
\hline 1 & 1 & 1 & 2 & 15 & 16 & 23 & 17 & 24 & 9 & 1 \\
\hline 6 & 7 & 3 & 10 & 17 & 17 & 24 & 24 & 27 & 10 & 1 \\
\hline 9 & 2 & 1 & 3 & 17 & 24 & 27 & 26 & 28 & 11 & 1 \\
\hline 8 & 2 & 2 & 4 & 18 & 26 & 28 & 28 & 30 & 12 & 1 \\
\hline 7 & 1 & 2 & 3 & 20 & 28 & 30 & 29 & 32 & 12 & 1 \\
\hline 10 & 1 & 1 & 2 & 22 & 29 & 32 & 30 & 33 & 11 & 1 \\
\hline \multicolumn{10}{|c|}{ Total Nt } & 8 \\
\hline
\end{tabular}

Kami juga melakukan percobaan numerik untuk membuktikan perbandingan algoritma usulan dengan aturan prioritas EDD. Percobaan dilakukan pada masalah flow shop untuk 2, 5, 10 dan 15 stagel mesin. Setiap stage kami lakukan percobaan sebanyak 5. Rekapitulasi percobaan numerik yang telah dilakukan dari perbandingan antara hasil algoritma baru ini dengan algoritma Earliest Due date (EDD) dapat dilihat pada

Tabel 7. Persentase job yang terlambat dari jumlah job di tiap percobaan dapat dilihat pada Gambar 1. Percobaan tersebut menunjukkan bahwa algoritma usulan dapat meminimasi jumlah job yang terlambat.

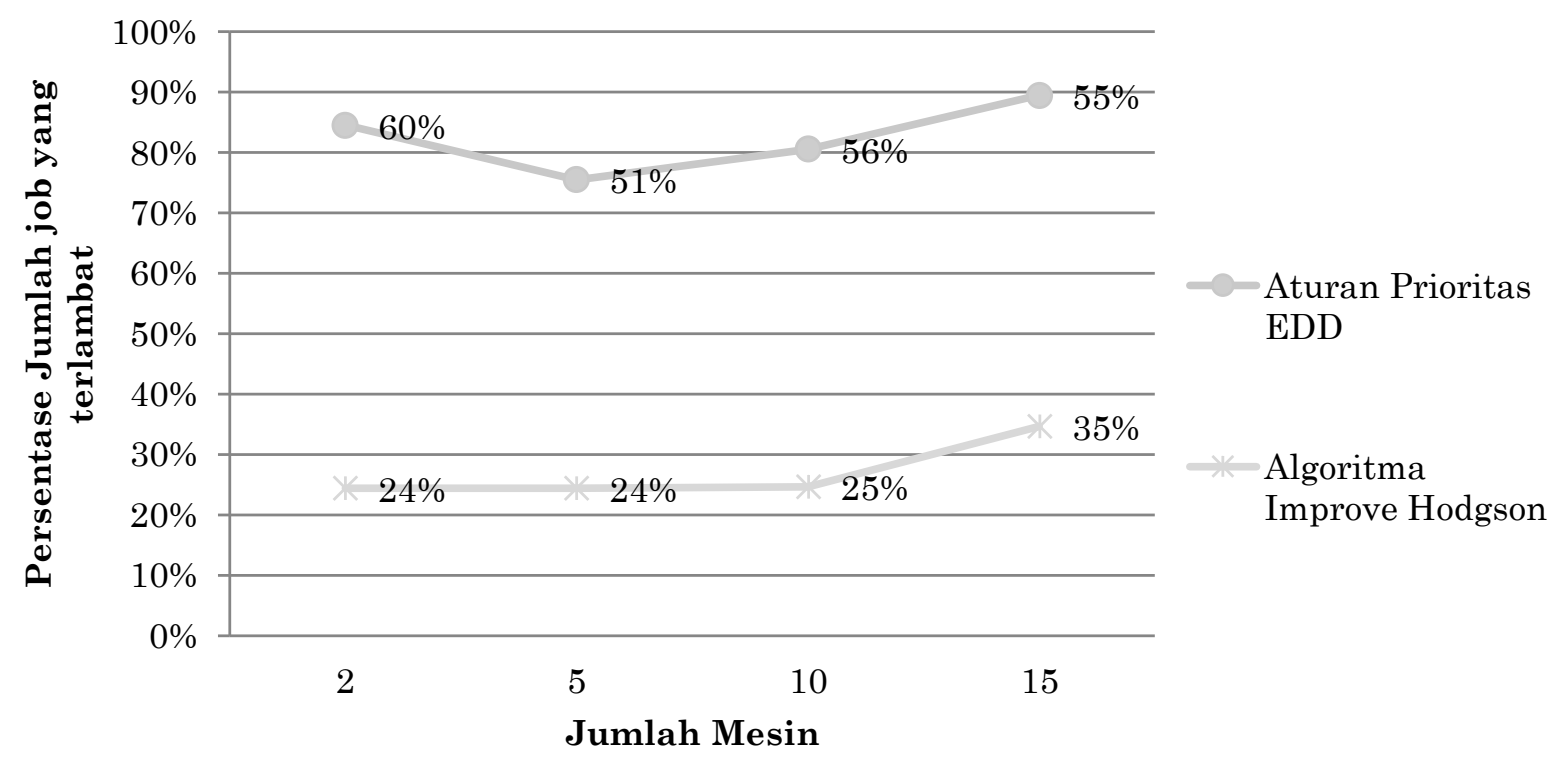

Gambar 1 Persentase job yang terlambat terhadap jumlah mesin 
Tabel 7 Rekapitulasi percobaan numerik

\begin{tabular}{ccccc}
\hline & & & \multicolumn{2}{c}{$\begin{array}{c}\text { Jumlah Job yang } \\
\text { terlambat }\end{array}$} \\
\cline { 4 - 5 } $\begin{array}{c}\text { Percobaan } \\
1\end{array}$ & $\begin{array}{c}\text { Jumlah } \\
\text { stage/mesin }\end{array}$ & $\begin{array}{c}\text { Jumlah } \\
\text { Job }\end{array}$ & $\begin{array}{c}\text { Improve } \\
\text { Hogson }\end{array}$ & $\begin{array}{c}\text { Prioritas } \\
\text { EDD }\end{array}$ \\
\hline 1 & 2 & 10 & 2 & 8 \\
2 & 5 & 8 & 3 & 5 \\
3 & 10 & 8 & 4 & 5 \\
4 & 15 & 6 & 3 & 4 \\
5 & 2 & 15 & 6 & 10 \\
6 & 5 & 13 & 4 & 8 \\
7 & 10 & 13 & 5 & 10 \\
8 & 15 & 11 & 6 & 8 \\
9 & 2 & 20 & 5 & 11 \\
10 & 5 & 18 & 1 & 8 \\
11 & 10 & 18 & 2 & 8 \\
12 & 15 & 16 & 6 & 7 \\
13 & 2 & 25 & 6 & 13 \\
14 & 5 & 23 & 7 & 11 \\
15 & 10 & 23 & 3 & 13 \\
16 & 15 & 21 & 5 & 11 \\
17 & 2 & 30 & 4 & 14 \\
18 & 5 & 28 & 5 & 11 \\
19 & 10 & 28 & 3 & 11 \\
20 & 15 & 26 & 2 & 10 \\
\hline
\end{tabular}

\section{Simpulan}

Dalam penelitian ini di simpukan bahwa pengembangan algoritma improve Hodgson yang dilakukan untuk meminimasi jumlah job yang terlambat memberikan hasil penjadwalan flow shop yang lebih baik dari aturan prioritas Earliest Due date (EDD). Algoritma improve Hodgson menghasilkan jumlah pekerjaan terlambat yang lebih minimum dibandingkan dengan aturan EDD. Diharapkan penelitian ini dapat membuka peluang untuk penelitian-penelitian selanjutnya untuk mengembangkan algoritma pada kasus flexible maupun hybrid flow shop agar menghasilkan solusi yang lebih baik lagi terutama dalam meminimasi jumlah job yang terlambat..

\section{Daftar Notasi}

$\mathrm{Tj} \quad$ : Total waktu proses

$t_{i j} \quad$ : Waktu proses yang diperlukan pekerjaan j di mesin $\mathrm{i}$.

Lj $\quad$ : Lateness pekerjaan j.

Cj $\quad$ : Completion time pekerjaan $\mathrm{j}$

dj : due date pekerjaan $\mathrm{j}$

$N j \quad$ : pekerjaan j terlambat $=1$ jika $\mathrm{Lj}>0$, selain itu 0

Nt : Jumlah pekerjaan yang terlambat 


\section{Referensi}

[1] K. R. Baker and D. Trietsch, Principles of sequencing and scheduling: John Wiley \& Sons, 2013.

[2] M. L. Pinedo, Scheduling: theory, algorithms, and systems: Springer Science \& Business Media, 2012.

[3] S. Harto, A. K. Garside, and D. M. Utama, "penjadwalan produksi menggunakan algoritma jadwal non delay untuk meminimalkan makespan studi kasus di cv. Bima mebel," Spektrum Industri, vol. 14, 2016.

[4] M. Husen, I. Masudin, and D. M. Utama, "Penjadwalan Job Shop Statik Dengan Metode Simulated Annealing Untuk Meminimasi Waktu Makespan," Spektrum Industri, vol. 13, 2015.

[5] K. R. Baker, Introduction to sequencing and scheduling: John Wiley \& Sons, 1974

[6] M. Pinedo, Planning and scheduling in manufacturing and services vol. 24: Springer, 2005.

[7] D. M. Utama, "Analisa Perbandingan Penggunaan Aturan Prioritas Penjadwalan Pada Penjadwalan Non Delay N Job 5 Machine," Research Report, vol. 1, 2017.

[8] C. Rajendran, "Heuristic algorithm for scheduling in a flowshop to minimize total flowtime," International Journal of Production Economics, vol. 29, pp. 65-73, 1993

[9] Y. Li, W. Ip, and D. Wang, "Genetic algorithm approach to earliness and tardiness production scheduling and planning problem," International Journal of Production Economics, vol. 54, pp. 65-76, 1998.

[10] S. M. Johnson, "Optimal two-and three-stage production schedules with setup times included," Naval Research Logistics (NRL), vol. 1, pp. 61-68, 1954.

[11] H. G. Campbell, R. A. Dudek, and M. L. Smith, "A heuristic algorithm for the $\mathrm{n}$ job, m machine sequencing problem," Management science, vol. 16, pp. B-630-B637, 1970.

[12] J. N. Gupta, "Heuristic algorithms for multistage flowshop scheduling problem," AIIE Transactions, vol. 4, pp. 11-18, 1972.

[13] D. G. Dannenbring, "An evaluation of flow shop sequencing heuristics," Management science, vol. 23, pp. 1174-1182, 1977.

[14] R. Logendran and N. Nudtasomboon, "Minimizing the makespan of a group scheduling problem: a new heuristic," International Journal of Production Economics, vol. 22, pp. 217-230, 1991.

[15] H. D. Pour, "A new heuristic for the n-job, m-machine flow-shop problem," Production Planning \& Control, vol. 12, pp. 648-653, 2001.

[16] M. Nawaz, E. E. Enscore, and I. Ham, "A heuristic algorithm for the m-machine, n-job flow-shop sequencing problem," Omega, vol. 11, pp. 91-95, 1983.

[17] I. Masudin, D. M. Utama, and F. Susastro, "Penjadwalan Flowshop Menggunakan Algoritma Nawaz Enscore Ham," Jurnal Ilmiah Teknik Industri, vol. 13, pp. 54-59, 2014.

[18] Z. Lomnicki, "A" branch-and-bound" algorithm for the exact solution of the threemachine scheduling problem," OR, pp. 89-100, 1965.

[19] J. Moore, "Sequencing $\mathrm{n}$ jobs on one machine to minimize the number of tardy jobs," Management Science, vol. 15, pp. 102-109, 1968. 
[20] J. C. Ho and Y.-L. Chang, "Minimizing the number of tardy jobs for m parallel machines," European Journal of Operational Research, vol. 84, pp. 343-355, 1995.

[21] E. Lodree Jr, W. Jang, and C. M. Klein, "A new rule for minimizing the number of tardy jobs in dynamic flow shops," European Journal of Operational Research, vol. 159, pp. 258-263, 2004.

[22] M. Azizoglu, S. Kondakci, and M. Köksalan, "Single machine scheduling with maximum earliness and number tardy," Computers \& Industrial Engineering, vol. 45 , pp. 257-268, 2003.

[23] R. M'Hallah and R. Bulfin, "Minimizing the weighted number of tardy jobs on a single machine," European Journal of Operational Research, vol. 145, pp. 45-56, 2003.

[24] R. M'Hallah and R. Bulfin, "Minimizing the weighted number of tardy jobs on a single machine with release dates," European Journal of Operational Research, vol. 176, pp. 727-744, 2007.

[25] S.-S. Li and R.-X. Chen, "Single-machine parallel-batching scheduling with family jobs to minimize weighted number of tardy jobs," Computers \& Industrial Engineering, vol. 73, pp. 5-10, 2014.

[26] A. Aydilek, H. Aydilek, and A. Allahverdi, "Algorithms for minimizing the number of tardy jobs for reducing production cost with uncertain processing times," Applied Mathematical Modelling, vol. 45, pp. 982-996, 2017.

[27] C.-C. Wu, W.-C. Lee, and T. Chen, "Heuristic algorithms for solving the maximum lateness scheduling problem with learning considerations," Computers \& Industrial Engineering, vol. 52, pp. 124-132, 2007. 